\title{
Locus Ceruleus Control of Slow-Wave Homeostasis
}

\author{
Chiara Cirelli, Reto Huber, Anupama Gopalakrishnan, Teresa L. Southard, and Giulio Tononi \\ Department of Psychiatry, University of Wisconsin, Madison, Madison, Wisconsin 53719
}

Sleep intensity is regulated by the duration of previous wakefulness, suggesting that waking results in the progressive accumulation of sleep need (Borbély and Achermann, 2000). In mammals, sleep intensity is reflected by slow-wave activity (SWA) in the nonrapid eye movement (NREM) sleep electroencephalogram, which increases in proportion to the time spent awake. However, the mechanisms responsible for the increase of NREM SWA after wakefulness remain unclear. According to a recent hypothesis (Tononi and Cirelli, 2003), the increase in SWA occurs because during wakefulness, many cortical circuits undergo synaptic potentiation, as evidenced by the widespread induction of long-term potentiation (LTP)-related genes in the brain of awake animals. A direct prediction of this hypothesis is that manipulations interfering with the induction of LTP-related genes should result in a blunted SWA response.

Here, we examined SWA response in rats in which cortical norepinephrine (NA) was depleted, a manipulation that greatly reduces the induction of LTP-related genes during wakefulness (Cirelli and Tononi, 2004). We found that the homeostatic response of the lower-range SWA was markedly and specifically reduced after NA depletion. These data suggest that the wake-dependent accumulation of sleep need is causally related to cellular changes dependent on NA release, such as the induction of LTP-related genes, and support the hypothesis that sleep SWA homeostasis may be related to synaptic potentiation during wakefulness.

Key words: cerebral cortex; DSP-4; noradrenergic; norepinephrine; sleep deprivation; slow-wave activity

\section{Introduction}

A key feature of sleep is its homeostatic regulation: the intensity of sleep increases in proportion to the duration of previous wakefulness. The best-characterized marker of sleep intensity is nonrapid eye movement (NREM) slow-wave activity (SWA), the spectral power of the electroencephalogram (EEG) in the frequency range of $0.5-4.5 \mathrm{~Hz}$ during NREM sleep (Borbély and Achermann, 2000). In mice, rats, hamsters, rabbits, cats, and humans, NREM SWA (SWA from now on) increases exponentially as a function of previous waking, peaks at the beginning of sleep, and declines exponentially with the progression of sleep (Daan et al., 1984; Tobler, 2000). Because SWA appears to reflect a need for sleep, it would be important to establish what aspect of wakefulness is responsible for its increase.

We have recently hypothesized that sleep need is tied to the induction of plastic changes during wakefulness (Tononi and Cirelli, 2003). This hypothesis proposes that waking behavior is associated with long-term potentiation (LTP) in many cortical circuits. During subsequent sleep, as a result of the increased synaptic weight, the amplitude and synchronization of cellular slow oscillations (Steriade et al., 2001) are enhanced, resulting in higher SWA. SWA, in turn, would promote synaptic downscaling (Turrigiano, 1999), with benefits for energy metabolism, signalto-noise ratios, and performance.

A link between waking synaptic potentiation and SWA ho-

Received Sept. 6, 2004; revised March 11, 2005; accepted March 28, 2005.

This work was supported by the National Institute of Mental Health. We thank Drs. Chris Nizzi and Pat Roseboom for their help with the HPLC analysis.

Correspondence should be addressed to Dr. Chiara Cirelli, Department of Psychiatry, University of Wisconsin, Madison, 6001 Research Park Boulevard, Madison, WI 53719. E-mail: ccirelli@wisc.edu. D01:10.1523/JNEUROSCI.4845-04.2005

Copyright $\odot 2005$ Society for Neuroscience $\quad$ 0270-6474/05/254503-09\$15.00/0 meostasis is suggested by several findings. Modeling studies show that an increase in synaptic weight in cortical circuits produces slow oscillations of higher amplitude (Hill and Tononi, 2005). It is also known that the amplitude of SWA closely parallels synaptic density in cortical gray matter during development and aging (Feinberg et al., 1990). Additional evidence comes from highdensity EEG studies in humans, which show that visuomotor learning, compared with a nonlearning task, produces a selective increase in SWA in the cortical area undergoing plastic changes (Huber et al., 2004). This local increase in SWA, which dissipates during sleep, is associated with improved performance the next morning (Huber et al., 2004). Finally, molecular studies have shown repeatedly that the expression of genes associated with the induction/maintenance of LTP is high during wakefulness and low during sleep (Cirelli and Tononi, 2000; Cirelli et al., 2004).

In this context, an important observation is that the induction of LTP-related genes during wakefulness can be reduced by lesions of the noradrenergic system (Cirelli et al., 1996; Cirelli and Tononi, 2000, 2004). Consistent with this observation, the noradrenergic system fires strongly during wakefulness, especially in relation to salient events and behavioral responses (Aston-Jones and Bloom, 1981b; Clayton et al., 2004; Rajkowski et al., 2004), but is near silent during sleep (Hobson et al., 1975; Aston-Jones and Bloom, 1981a). Also, norepinephrine (NA) promotes LTP induction in vivo, and noradrenergic lesions impair plasticity (Gu, 2002) and memory acquisition (Ogren et al., 1980; Archer et al., 1983; Ho et al., 1995; al-Zahrani et al., 1997).

To the extent that the induction of LTP-related genes during wakefulness is a reliable marker of the occurrence of synaptic potentiation, it follows that, if such induction is reduced by noradrenergic lesions, the homeostatic regulation of SWA should be blunted. Here, we measured SWA homeostasis in controls and in 
rats treated with the neurotoxin $\mathrm{N}$-(2-chloroethyl)- $\mathrm{N}$-ethyl-2bromobenzylamine (DSP-4), which depletes the cerebral cortex of NA (Fritschy and Grzanna, 1989).

\section{Materials and Methods}

Animal groups and sleep recording. Male inbred WKY rats (250-300 g) were pretreated with the selective serotonin (5-HT) uptake inhibitor fluoxetine $(10 \mathrm{mg} / \mathrm{kg}$, i.p.) to minimize the effects of DSP-4 on serotoninergic terminals and injected $30 \mathrm{~min}$ later with either saline or DSP-4 (50 $\mathrm{mg} / \mathrm{kg}$, i.p.; Sigma, St. Louis, MO) (see below). One week later, under pentobarbital anesthesia $(60-75 \mathrm{mg} / \mathrm{kg}$, i.p.), rats were implanted with screw electrodes on the dura over the frontal, parietal, and occipital cortex to record the EEG and silver electrodes in the neck muscles of both sides to record the electromyogram. After surgery, rats were housed individually in sound-proof recording cages in which lighting and temperature were kept constant [ $12 \mathrm{~h}$ light/dark (LD) cycle; lights on at 10 A.M.; $24 \pm 1{ }^{\circ} \mathrm{C}$; food and drink available ad libitum]. Immediately after recovery from anesthesia, rats were connected by means of a flexible cable and a commutator (Airflyte, Bayonne, NJ) to a Grass electroencephalograph (model 15LT; Astro-Med, West Warwick, RI) and recorded continuously for 2-3 weeks. The EEG and EMG signals were amplified, conditioned by analog filters (high-pass filter, $-3 \mathrm{~dB}$ at $0.016 \mathrm{~Hz}$; low-pass filter, $-3 \mathrm{~dB}$ at $40 \mathrm{~Hz}$; less than $-35 \mathrm{~dB}$ at $128 \mathrm{~Hz}$ ), sampled at $512 \mathrm{~Hz}$, digitally filtered [EEG: high-pass filter, $0.3 \mathrm{~Hz}$; low-pass finite impulse response (FIR) filter, $25 \mathrm{~Hz}$; EMG: band-pass FIR filter, $20-50 \mathrm{~Hz}$ ], and stored with a resolution of $256 \mathrm{~Hz}$. Each day from 10 to 10:30 A.M., all rats were gently handled and exposed to a new object to become familiar with the sleep-deprivation procedure. At least 1 week after surgery, saline-treated and DSP-4-treated rats underwent the following experimental protocol: (1) one $24 \mathrm{~h}$ baseline recording in $12 \mathrm{~h} \mathrm{LD}$ conditions (starting at 10 A.M.); (2) one $24 \mathrm{~h}$ recording in $12 \mathrm{~h} \mathrm{LD}$ conditions including $6 \mathrm{~h}$ of sleep deprivation (starting at 10 A.M.) followed by $18 \mathrm{~h}$ of recovery sleep; (3) one $24 \mathrm{~h}$ baseline recording in dark/dark (DD) conditions (starting at 10 A.M., but lights remained off; lights were turned on again the following day at 10 A.M.); (4) one $24 \mathrm{~h}$ recording in DD conditions (starting at 10 A.M., but lights remained off) including $6 \mathrm{~h}$ of sleep deprivation (starting at 10 A.M.) followed by $18 \mathrm{~h}$ of recovery sleep (lights were turned on again the following day at 10 A.M.). In all animals, the sequence of the experiments was from 1 to 4 , with each recording session spaced 3-4 d apart from the previous one. Rats were sleep deprived by introducing novel objects in their cages. Every new object was delivered just after the first signs of synchronization in the EEG signal. Animal protocols followed the National Institutes of Health Guide for the Care and Use of Laboratory Animals and were in accordance with institutional guidelines.

Assay of norepinephrine, dopamine, and serotonin. Rats were anesthetized deeply with isoflurane (within $2 \mathrm{~min}$ ) and decapitated. The head was cooled in liquid nitrogen, and the whole brain was rapidly removed and placed on ice. Cerebral cortex, hippocampus, and cerebellum were dissected out and frozen immediately by immersion of the tubes in liquid nitrogen. All samples were stored at $-80^{\circ} \mathrm{C}$ until the time of the assay. Levels of NA, dopamine (DA), and 5-HT were measured in the left cerebral cortex using HPLC with electrochemical detection using the method of Fuertes et al. (2000). Briefly, the left cerebral cortex from each rat was homogenized in $0.02 \mathrm{M}$ perchloric acid using a motor-driven PotterElvehjem homogenizer. After centrifugation at 13,000 rpm for $5 \mathrm{~min}$ at $4^{\circ} \mathrm{C}$, the clear supernatant was filtered through a $0.22 \mu \mathrm{m}$ Millex-GP filter unit (Millipore, Bedford, MA), and $15 \mu \mathrm{l}$ were injected into a $3 \mu \mathrm{m}$ C18 reverse-phase column (ESA, Chelmsford, MA) in the HPLC system (ESA) in which NA, DA, and 5-HT were analyzed. The mobile phase consisted of $0.1 \mathrm{M}$ sodium phosphate, $50 \mathrm{~mm}$ citric acid, $1.8 \mathrm{~mm}$ 1 -octanesulfonic acid, $10 \%$ acetonitrile, adjusted to $\mathrm{pH} 3.01$, and the flow rate was $0.5 \mathrm{ml} / \mathrm{min}$. Values were expressed as nanograms per milliliter of tissue homogenate, based on internal standard measurements using dihydroxybenzylamine. The nonparametric Mann-Whitney $U$ test was used for the statistical analysis of the results.

Sleep stages and EEG power spectral analysis. Sleep stages were scored visually based on $4 \mathrm{~s}$ epochs. Epochs containing EEG artifacts were marked and omitted from additional analysis of the spectra. EEG power spectra of consecutive $4 \mathrm{~s}$ epochs (fast Fourier transform routine; Hanning window) were calculated for frontal, parietal, and occipital EEG derivations within the frequency range of $0.25-20.0 \mathrm{~Hz}$. The final analysis and all the figures refer to the parietal derivation because it provided the best quality recordings data for all the animals in all four experimental conditions. The duration and frequency of episodes was computed based on minimal interruption criteria previously used in rats (Franken et al., 1991). The minimum episode duration for waking, NREM sleep, and rapid eye movement (REM) sleep was 32, 24, and $4 \mathrm{~s}$, respectively. Differences between the experimental groups were analyzed by two-way ANOVA with factors "treatment" (saline or DSP-4) and "time interval." Differences between conditions were analyzed by two-way ANOVA with factors condition (baseline vs sleep deprivation) and time interval. Contrasts were tested by post hoc two-tailed $t$ tests only if the main factor or interaction of the ANOVA reached significance. Brief awakenings were defined as uninterrupted waking episodes of one to up to four $4 \mathrm{~s}$ epochs. To correct for differences in the amount of sleep in a given time interval, the number of brief awakenings was expressed per hour of total sleep.

\section{Results}

\section{DSP-4 treatment selectively decreases cortical NA levels}

To lesion the locus ceruleus (LC) system, we used the neurotoxin DSP-4, which can be administered intraperitoneally. All the available evidence suggests that DSP-4 causes a selective depletion of cortical NA. DSP-4 does not have cytotoxic effects (Dudley et al., 1990; Yamamoto et al., 2001), does not cause synaptic loss in the cerebral cortex of adult animals (Matsukawa et al., 2003), has no effect on cholinergic transmission (Riekkinen et al., 1992; Yamamoto et al., 2001), and only slightly reduces cortical glutamatergic transmission (Yamamoto et al., 2001). However, as discussed in detail in a recent study (Cirelli and Tononi, 2004), DSP-4 has some potential limitations. Several weeks after DSP-4 treatment, damaged NA fibers are capable of restoring some of their lost functions (Fritschy and Grzanna, 1992). Moreover, the efficacy of the DSP-4 lesion can vary from animal to animal and an incomplete lesion (NA depletion of $<80 \%$ ) can cause "paradoxical" effects resulting from compensatory mechanisms such as the upregulation of adrenergic receptors (Robbins and Everitt, 1995). To overcome these limitations, all animals in this study were killed within the first 4 weeks after the DSP-4 injection, and HPLC measurements were used to determine the efficiency as well as the specificity of the treatment. Figure 1 shows that in 16 of the 25 DSP-4-treated animals, cortical NA levels were reduced to $<10 \%(8.8 \% \pm 2.0$; mean \pm SEM $)$ of the values in saline-treated controls. In the remaining nine DSP-4-treated animals, in contrast, cortical NA depletion was only partial $(56.4 \% \pm 12.2$; data not shown). In the 16 DSP-4 rats with almost complete NA de-

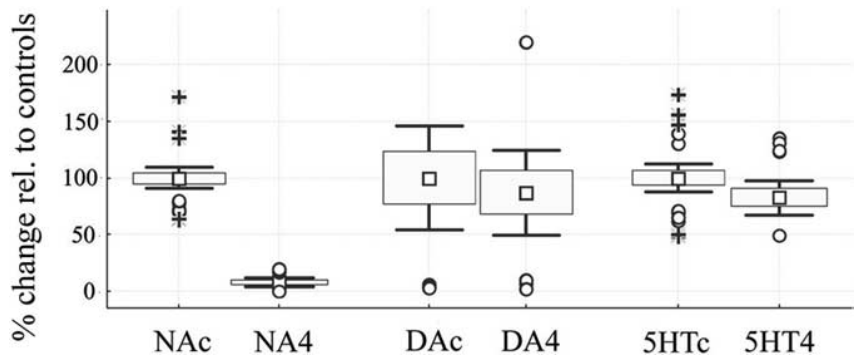

Figure 1. Levels of NA, DA, and 5-HT in the left cerebral cortex of saline-treated rats ( $c ; n=$ 27) and rats treated effectively with DSP-4 $(4 ; n=16)$. NA, DA, and 5 -HT were measured using $\mathrm{HPLC}$ with electrochemical detection. Values (mean \pm SEM) in DSP-4-treated rats are expressed as percentage relative (rel.) to saline-treated controls (100\%). NA, 8.8 $\pm 2.0 ; \mathrm{DA}, 87 \pm$ 20; 5 -HT, $83 \pm 7$. Boxes, Mean \pm SEM; open circles, outliers; crosses, extremes. Mann-Whitney $U$ test: $\mathrm{NA}, p<0.00001 ; \mathrm{DA}, p=0.97 ; 5-\mathrm{HT}, p=0.12$. 

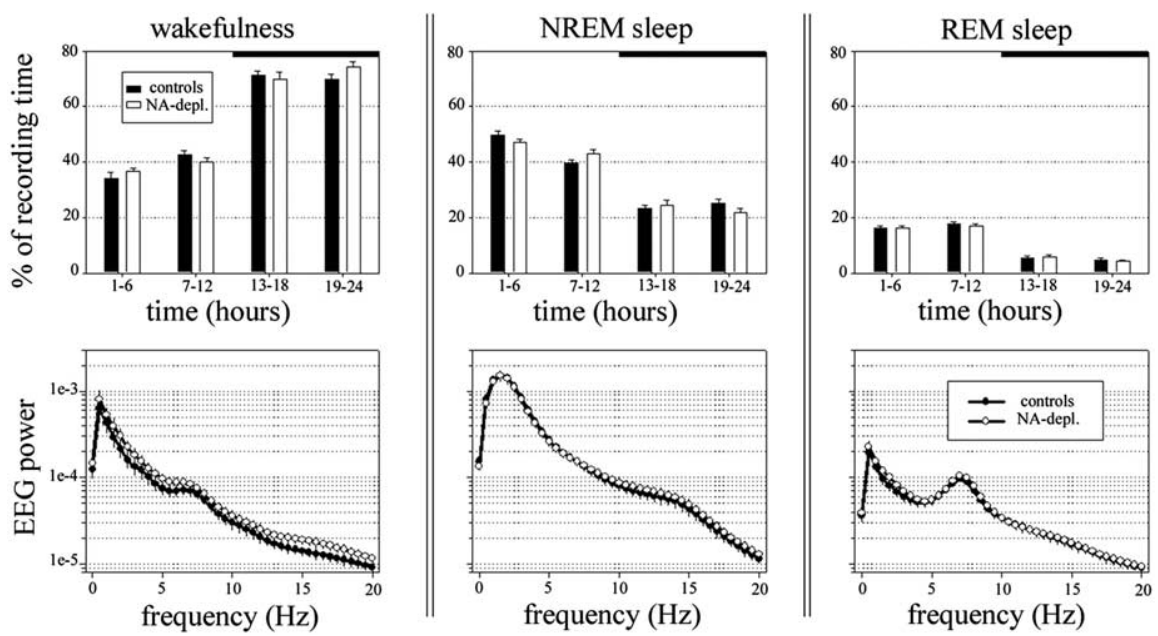

Figure 2. Effects of NA depletion on behavioral states [controls, $n=27$; NA depleted (depl.), $n=16$ ]. In this and the following figures, NA-depleted rats are those animals in which NA levels were $<10 \%$ relative to saline-treated controls. Top, Time course of the amount of wakefulness, NREM sleep, and REM sleep during $24 \mathrm{~h}$ of baseline ( $12 \mathrm{~h}$ light/dark condition). Bars represent $6 \mathrm{~h}$ mean values (+SEM) expressed as a percentage of recording time. Bottom, Mean absolute EEG power values $\left(\mu \mathrm{V}^{2} / 0.5 \mathrm{~Hz}\right)$ of the $24 \mathrm{~h}$ baseline during wakefulness, NREM, and REM sleep. Values represent EEG power per $0.5 \mathrm{~Hz}$ bin ( \pm SEM) on a logarithmic scale (parietal derivation)

Table 1. Effects of NA depletion on vigilance states

\begin{tabular}{|c|c|c|c|c|}
\hline & \multicolumn{2}{|l|}{ Controls } & \multicolumn{2}{|l|}{ NA depleted } \\
\hline & LD & DD & LD & DD \\
\hline$n(S D)$ & $27(13)$ & $8(8)$ & $16(12)$ & $7(7)$ \\
\hline \multicolumn{5}{|l|}{ Waking } \\
\hline \multicolumn{5}{|l|}{$B L$} \\
\hline$L(1-6)$ & $34.2(2.0)$ & $38.1(2.2)$ & $36.5(1.9)$ & $40.7(2.2)$ \\
\hline $\mathrm{L}(7-12)$ & $42.7(1.3)$ & $45.3(3.8)$ & $40.1(1.7)$ & $46.8(2.5)$ \\
\hline D (13-24) & $70.6(1.2)$ & $63.0(4.1)$ & $72.1(2.7)$ & $69.6(4.3)$ \\
\hline \multicolumn{5}{|l|}{ SD } \\
\hline $6 \mathrm{hSD}(1-6)$ & $94.0(1.4)$ & $98.0(0.7)$ & $94.6(1.7)$ & $97.5(1.0)$ \\
\hline $\operatorname{Rec} L(7-12)$ & $30.2(1.1)^{+}$ & $26.7(2.4)^{+}$ & $30.3(3.3)^{+}$ & $27.1(2.3)^{+}$ \\
\hline $\operatorname{Rec} D(13-24)$ & $61.4(1.8)$ & $55.8(3.2)$ & $63.4(1.4)$ & $55.4(2.9)$ \\
\hline \multicolumn{5}{|l|}{ NREM sleep } \\
\hline \multicolumn{5}{|l|}{$\mathrm{BL}$} \\
\hline $\mathrm{L}(1-6)$ & $49.6(1.4)$ & $46.9(2.0)$ & $47.2(1.5)$ & $44.0(1.8)$ \\
\hline $\mathrm{L}(7-12)$ & $39.8(0.9)$ & $40.2(3.4)$ & $42.9(1.9)$ & $37.9(2.2)$ \\
\hline$D(13-24)$ & $24.3(0.9)$ & $31.3(4.1)$ & $22.8(2.1)$ & $25.1(3.8)$ \\
\hline \multicolumn{5}{|l|}{ SD } \\
\hline $6 \mathrm{hSD}(1-6)$ & $5.5(1.3)$ & $1.9(0.6)$ & $5.0(1.6)$ & $2.5(1.0)$ \\
\hline $\operatorname{Rec} L(7-12)$ & $52.8(1.2)^{+}$ & $55.6(1.9)^{+}$ & $51.9(2.9)^{+}$ & $51.7(2.7)^{+}$ \\
\hline $\operatorname{Rec} D(13-24)$ & $29.2(1.6)$ & $33.1(3.0)$ & $27.4(1.5)$ & $33.2(2.5)$ \\
\hline \multicolumn{5}{|l|}{ REM sleep } \\
\hline \multicolumn{5}{|l|}{$\mathrm{BL}$} \\
\hline $\mathrm{L}(1-6)$ & $16.2(0.9)$ & $15.1(1.5)$ & $16.3(1.0)$ & $15.3(0.9)$ \\
\hline $\mathrm{L}(7-12)$ & $17.6(0.8)$ & $14.5(1.4)$ & $17.0(0.9)$ & $15.3(1.1)$ \\
\hline$D(13-24)$ & $5.0(0.4)$ & $5.7(0.4)$ & $5.1(0.7)$ & $5.4(0.7)$ \\
\hline \multicolumn{5}{|l|}{ SD } \\
\hline $6 \mathrm{~h} \mathrm{SD}(1-6)$ & $0.5(0.2)$ & $0.1(0.1)$ & $0.3(0.2)$ & $0.0(0.0)$ \\
\hline $\operatorname{Rec} L(7-12)$ & $17.0(0.7)$ & $17.6(1.1)$ & $17.8(1.0)$ & $21.2(1.2)^{+*}$ \\
\hline $\operatorname{Rec} D(13-24)$ & $9.4(0.6)$ & $11.0(0.6)$ & $9.1(0.7)$ & $11.4(0.7)$ \\
\hline
\end{tabular}

Wakefulness, NREM, and REM sleep in saline-treated (Controls) and NA-depleted rats under LD (12 h) or DD conditions. Values refer to the $12 \mathrm{~h}$ light (L 1-6, $\mathrm{L} 7-12$ ) and dark (D 13-24) periods during baseline (BL), $6 \mathrm{~h}$ of sleep deprivation (6h SD), the remaining $6 \mathrm{~h}$ of the light period after sleep deprivation (Rec $\mathrm{L}$ $7-12$ ), and the subsequent dark period (Rec D 13-24). All values (mean \pm SEM) are expressed as percentage of total recording time. N indicates the number of animals contributing to the baseline values; $S D$ refers to the subgroups of animals subjected to sleep deprivation. The statistical analysis was done separately for the first and second $6 \mathrm{~h}$ of the light period and for the entire $12 \mathrm{~h}$ of the dark period.

${ }^{*} p<0.05$; controls versus NA depleted; unpaired $t$ test.

${ }^{+} p<0.05$; baseline versus recovery; paired $t$ test.

pletion, the levels of serotonin and dopamine were not significantly reduced relative to controls (Fig. 1). Thus, in line with previous work (Dudley et al., 1990; Cirelli and Tononi, 2004), we found that DSP-4 lesions can produce an almost complete and primarily selective depletion of cortical NA without affecting the serotonergic or the dopaminergic system.

\section{DSP-4 does not affect daily amount of sleep and the overall EEG power spectrum}

All animals recovered overnight from the DSP-4 injection and increased their body weight during the 4 weeks after the treatment. All rats were recorded continuously for several days after adaptation to the recording environment to establish baseline percentages and distributions of wakefulness, NREM sleep, and REM sleep. As expected under a $12 \mathrm{~h}$ light/dark schedule, rats were asleep for most of the light period and awake for most of the dark period. Moreover, as described previously (Cirelli et al., 1996; Cirelli and Tononi, 2000, 2004), overall daily percentages of behavioral states 2-4 weeks after the DSP-4 injection did not differ between saline-treated and NA-depleted animals (Fig. 2, top; Table 1). The number of NREM sleep, REM sleep, and waking episodes, as well as their duration, were also similar in the two experimental groups (data not shown), as was the overall EEG power spectrum during NREM sleep, REM sleep, and wakefulness, which did not differ across animal groups in any frequency bin (Fig. 2, bottom).

\section{Cortical NA depletion is associated with a decrease in slow-wave homeostasis after sleep deprivation}

To determine whether an almostcomplete depletion of cortical NA affected slow-wave homeostasis, saline-treated and NA-depleted animals were sleep deprived during the first $6 \mathrm{~h}$ of the light period and then allowed to sleep ad libitum. As shown in Table 1, during the $6 \mathrm{~h}$ of sleep deprivation, the exposure to novel objects was able to keep all rats awake for $>94 \%$ of the time. Table 1 also shows that after sleep deprivation, both saline-treated and NA-depleted animals showed a similarly significant increase in the duration of NREM sleep, which was restricted to the last $6 \mathrm{~h}$ of the light period. REM sleep duration, on the other hand, showed a similar trend to increase during the dark period in both groups but without reaching statistical significance.

Figure 3 shows SWA $(0.5-4.5 \mathrm{~Hz})$ during the first $18 \mathrm{~h}$ after sleep deprivation expressed as the percentage change relative to the $24 \mathrm{~h}$ baseline mean. As expected, SWA increased after sleep deprivation, and in both experimental groups, its values remained significantly above the $24 \mathrm{~h}$ baseline value for $4 \mathrm{~h}$ (paired $t$ test; $p<0.05$ ). More importantly, Figure 3 also shows 


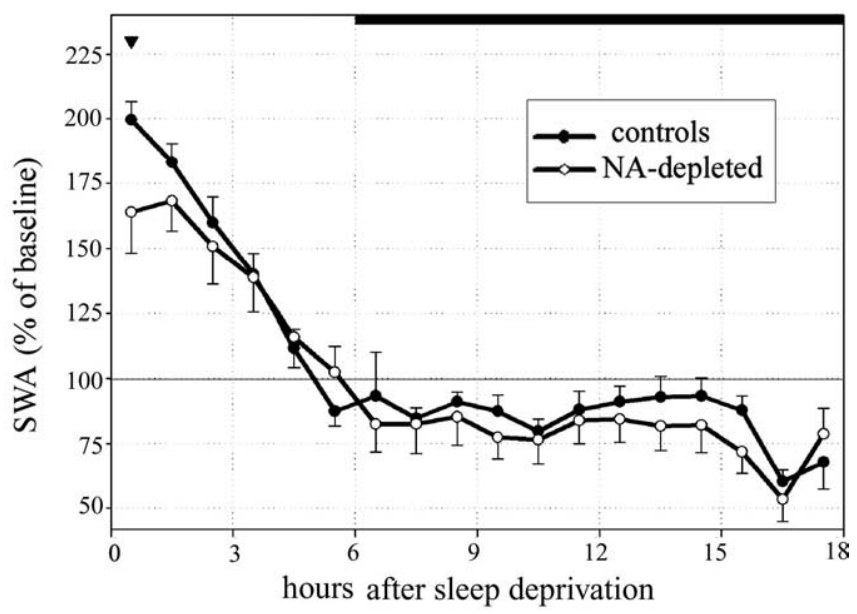

Figure 3. Time course of SWA $(0.5-4.5 \mathrm{~Hz})$ during NREM sleep after $6 \mathrm{~h}$ of sleep deprivation (controls, $n=13$; NA depleted, $n=12$ ). Curves connect $1 \mathrm{~h}$ mean values ( \pm SEM) of SWA expressed for every individual animal as a percentage of the $24 \mathrm{~h}$ baseline mean. Triangles indicate differences between the two experimental groups ( $p<0.05$; two-tailed unpaired $t$ test after significance in two-way ANOVA).

that during the first hour after sleep deprivation, the SWA homeostatic response was significantly smaller in NA-depleted animals than in controls.

Several previous animal studies have shown that the increase in SWA after sleep deprivation is most prominent (Tobler and Borbély, 1990), longest lasting (Tobler et al., 1997; Huber et al., 2000), or even limited to the lower-range SWA ( $<2 \mathrm{~Hz}$ ) (Franken et al., 1991). The lower-range SWA overlaps with the frequency range of the slow oscillation $(\leq 1 \mathrm{~Hz})$, the fundamental intracellular phenomenon that occurs in all cortical neurons during NREM sleep (Steriade et al., 2001). Moreover, a recent human study (Huber et al., 2004) found that the local increase in SWA after the learning of a motor task was most prominent in the lower range $(0.25-2 \mathrm{~Hz})$. Thus, the lower-range SWA appears to be the most sensitive indicator of the EEG changes occurring during recovery sleep. To determine whether the blunted SWA response in NA-depleted animals encompassed the full range of frequencies $(0.5-4.5 \mathrm{~Hz})$ or was specific for the lower-range SWA, we analyzed the entire EEG power spectrum density of NREM sleep during the first $2 \mathrm{~h}$ after sleep deprivation. Figure 4 (top) shows that the blunted homeostatic SWA response in NAdepleted animals is specific for the lower-range SWA, between 0.5 and $1.5 \mathrm{~Hz}$ (top). Figure 4 also shows (bottom) that the blunted response in the lower-range SWA in NA-depleted animals persists for $2 \mathrm{~h}$ after sleep deprivation.

To rule out nonspecific effects of the DSP-4 treatment per se, lower-range SWA was compared between saline-treated controls and those DSP-4-treated animals in which the neurotoxin produced only a partial decrease of cortical NA levels. Because these animals did not reach the threshold of $90 \%$ NA depletion, they were excluded from the main study (see above). In partially NAdepleted rats, the increase in lower-range SWA after sleep deprivation was as prominent and as sustained as in saline-treated rats ( $1 \mathrm{~h}$ maximal value after sleep deprivation as percentage of $24 \mathrm{~h}$ baseline: partially NA-depleted rats, $191.1 \% \pm 29.8, n=4$; saline-treated rats, $209.4 \% \pm 13.9, n=12$; in both experimental groups, lower-range SWA peaked during the second hour after sleep deprivation).
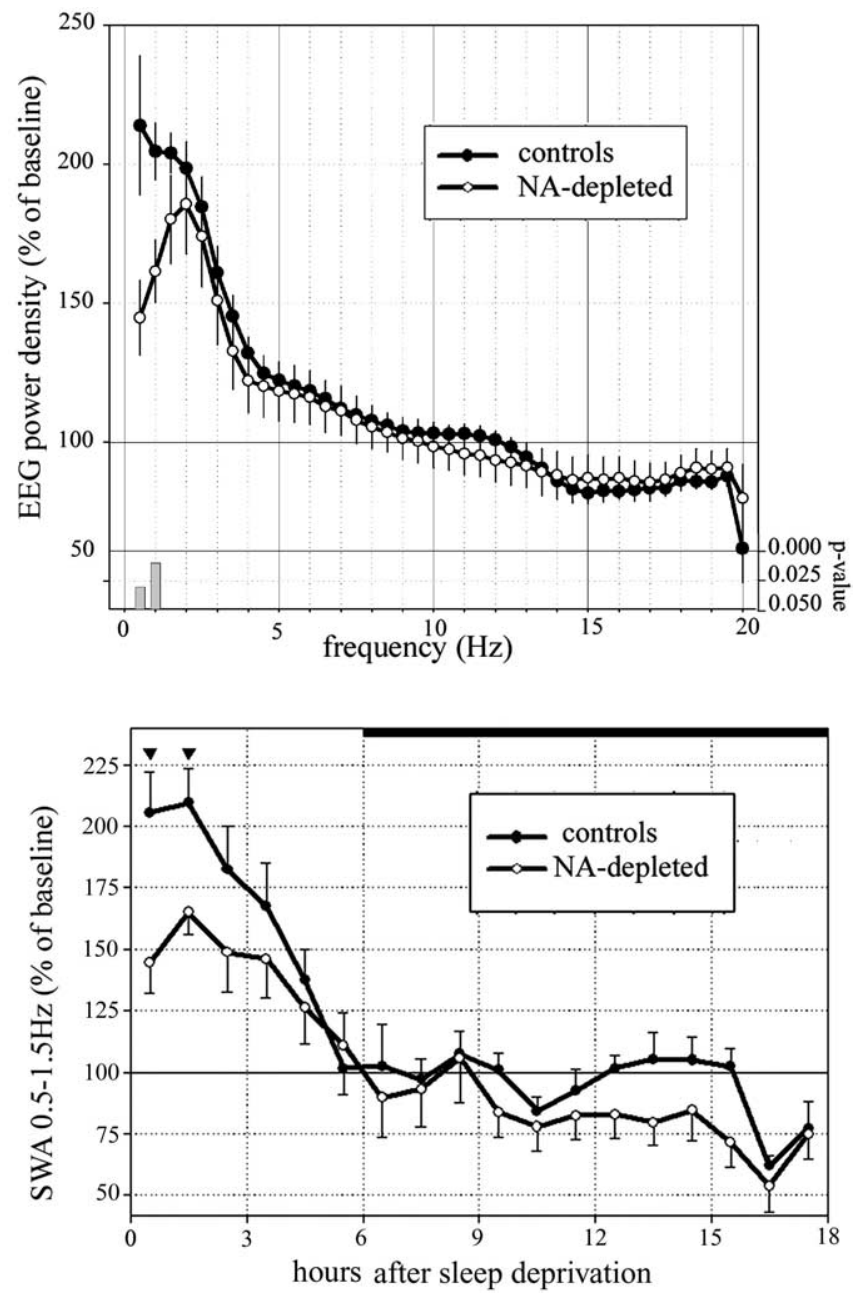

Figure 4. Top, Effects of NA depletion on EEG power density during NREM sleep after $6 \mathrm{~h}$ of sleep deprivation (controls, $n=13$; NA depleted, $n=12$ ). Curves connect means ( \pm SEM) of relative power density in the first $2 \mathrm{~h}$ after sleep deprivation expressed as percentage of power in the same frequency bin during the $24 \mathrm{~h}$ baseline. Bottom bars indicate frequency bins for which power in NA-depleted rats was significantly different from control animals (unpaired $t$ test; $p<0.05$ ). Bottom, Time course of the EEG power density in the low-frequency-range $(0.5-1.5 \mathrm{~Hz}$ ) SWA during NREM sleep after $6 \mathrm{~h}$ of sleep deprivation (controls, $n=13$; NA depleted, $n=12$ ). Curves connect $1 \mathrm{~h}$ mean values ( \pm SEM) of SWA expressed for every individual animal as a percentage of the $24 \mathrm{~h}$ baseline mean. Triangles indicate differences between the two experimental groups ( $p<0.05$; two-tailed unpaired $t$ test after significance in two-way ANOVA).

\section{Cortical NA depletion blunts the lower-range SWA increase after spontaneous wakefulness}

Two sets of evidence indicate that SWA is a measure of sleep need. The first is that SWA increases when the waking period is prolonged beyond its physiological duration (i.e., when sleep deprivation occurs). The second is that, within the $24 \mathrm{~h}$ cycle, SWA reaches its highest values at the beginning of the sleep phase (i.e., after the major waking period). We tested therefore whether NAdepleted animals showed a blunted SWA response not only after being sleep deprived, but also after a waking period of physiological duration. As expected, in both groups of animals SWA peaked shortly after lights on (i.e., at the beginning of the major sleep phase) and decreased thereafter (data not shown). The increase in SWA, however, was again more pronounced in salinetreated rats than in NA-depleted animals. As before, the effect was specific for SWA in the low frequency range $(0.5-1.5 \mathrm{~Hz}$; data not shown). As shown in Figure 5, the lower-range SWA showed not 


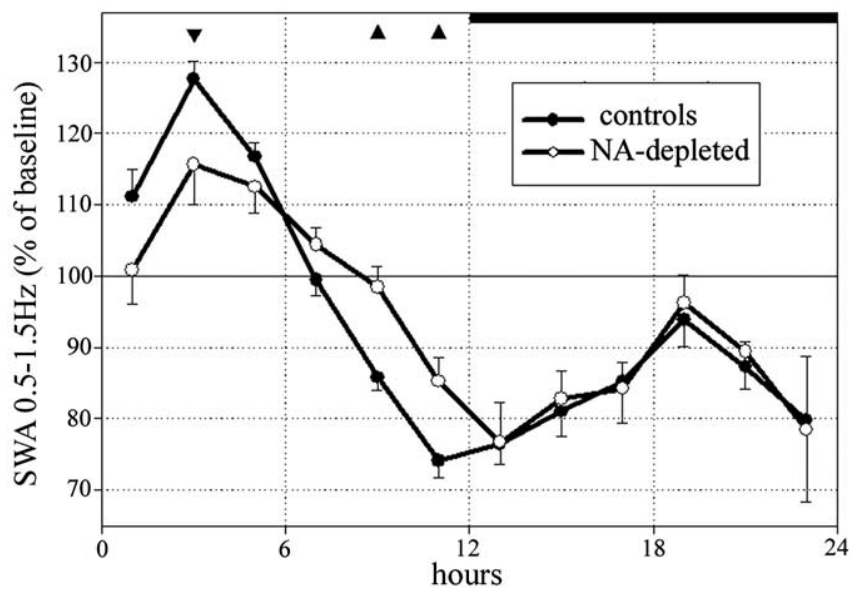

Figure 5. Time course of the EEG power density in the low-range $(0.5-1.5 \mathrm{~Hz})$ SWA in NREM sleep during baseline (controls, $n=27$; NA depleted, $n=16$ ). Curves connect $2 \mathrm{~h}$ mean values ( \pm SEM) of SWA expressed for every individual animal as a percentage of the $24 \mathrm{~h}$ baseline mean (100\%). Triangles indicate differences between the two experimental groups ( $p<0.05$; two-tailed unpaired $t$ test after significance in two-way ANOVA).

only a smaller increase at the beginning of the light period, but also a smaller decrease below the $24 \mathrm{~h}$ mean value during the second half of the light period.

\section{The effects of light on SWA do not explain why NA-depleted rats show a blunted lower-range SWA response}

Tobler et al. (1994) found that SWA in NREM sleep is significantly enhanced when rats are sleep recorded in constant darkness. Thus, because light has a negative impact on SWA, we tested whether an increased sensitivity to light in NA-depleted rats could account for their blunted response in the lower-range SWA. Saline-treated and NA-depleted rats kept in $12 \mathrm{~h} \mathrm{LD} \mathrm{con-}$ ditions were switched to DD at the beginning of the subjective day (10 A.M.) and allowed to sleep ad libitum in the dark for the following $24 \mathrm{~h}$. In DD, maximal $1 \mathrm{~h}$ mean values of the lowerrange SWA during NREM sleep peaked earlier in NA-depleted rats than in controls (NA depleted, 1:00 P.M. \pm 24 min; controls, 2:18 P.M. $\pm 24 \mathrm{~min}$; $t$ test, $p=0.03$ ) but reached higher levels in controls (NA depleted, $118.8 \pm 6.7$; controls, $141.3 \pm 3.7$; percentage of $24 \mathrm{~h}$ baseline in LD; $p<0.05 ; n=7$ per group; data not shown). Thus, the blunted lower-range SWA response observed in NA-depleted rats during baseline sleep is independent of whether light is present and is not because of the fact that these animals are more sensitive to the negative effects of light on SWA. In fact, in controls, the maximal values reached by the lowerrange SWA during NREM sleep were higher when the animals slept in DD than when they slept in LD (LD, 121.4 \pm 6.0 ; DD, $141.3 \pm 3.7 ; p<0.005)$ and peaked later (LD, 12:42 P.M. \pm 12 ; DD, 2:18 P.M. $\pm 24 ; p=0.001)$. In NA-depleted rats, on the other hand, there was no significant difference between lowerrange SWA peak levels during NREM sleep when the animals slept in DD relative to when they slept in LD (DD, $118.8 \pm 6.7$; $\mathrm{LD}, 107.0 \pm 6.2 ; p=0.2$ ), and maximal values were reached at the same circadian time (LD, 12:30 P.M. \pm 12 min; DD, 1:00 P.M. \pm $24 \min ; p=0.246$ ).

The potential effects of light on SWA were also studied in saline-treated and NA-depleted rats first deprived of sleep for $6 \mathrm{~h}$ in DD starting at the beginning of the subjective day (10 A.M.) and then allowed to sleep ad libitum in the dark for the following $18 \mathrm{~h}$ (see Materials and Methods). In contrast to what was observed during baseline, peak values of the lower-range SWA after sleep deprivation in DD were reached earlier in controls than in NA-depleted rats (controls, 5:54 P.M. \pm 6 min; NA depleted, 6:24 P.M. $\pm 12 \mathrm{~min} ; p=0.04)$. More importantly, however, and consistent with the baseline data, the maximal values reached by the lower-range SWA were significantly higher in controls than in NA-depleted animals $(257.0 \pm 5.1$ vs $201.0 \pm 5.8 ; p<0.05 ; n=$ 7 per group; data not shown). Thus, even after sleep deprivation, the blunted lower-range SWA response in NA-depleted rats is not caused by an increased sensitivity to light.

\section{Cortical NA depletion does not affect the time course of lower-range SWA within NREM sleep episodes}

The fact that the lower-range SWA at the beginning of the sleep phase peaked at lower levels in NA-depleted rats is not necessarily an indication that these animals are unable to attain as much SWA as controls. Another possibility is that, when transitioning from waking to NREM sleep, their lower-range SWA simply takes longer to reach its maximum. To determine whether this was the case, all NREM sleep episodes longer than 4 min occurring during the $24 \mathrm{~h}$ baseline recording were pooled for each experimental group, and the time course of lower-range SWA was measured at the transition between waking and NREM. The lower-range SWA was compared between the last minute before the waking-toNREM transition and the 4 min after the transition. As shown in Figure 6, in both experimental groups, the lower-range SWA sharply increased at the transition to NREM sleep and reached an asymptotic level after $\sim 2 \mathrm{~min}$. The figure also shows that there was no difference between controls and NA-depleted rats in the dynamics underlying the generation of lower-range SWA (i.e., lower-range SWA took the same time to reach its peak levels in both groups). This was true both during baseline (Fig. 6, top) as well as after sleep deprivation (Fig. 6, bottom).

Another potential reason for smaller lower-range SWA values in NA-depleted rats would be sleep fragmentation. If this were the case, the discharge of the lower-range SWA pressure during the light phase would be delayed, and the overall relative changes in the lower-range SWA would to be smaller. As shown in Figure 7 (top), the duration of NREM sleep episodes did not differ during baseline between experimental groups and showed the same increase after sleep deprivation. The number of sleep episodes was also similar in the two groups (Fig. 7, middle). Moreover, at each time point during both baseline and after sleep deprivation, the number of brief awakenings was not significantly different in NA-depleted rats relative to controls. Thus, the blunted lowerrange SWA response at sleep onset in NA-depleted rats is not a consequence of a slower build-up, nor of a more fragmented sleep, but reflects a decrease in the homeostatic response of these animals.

\section{Discussion}

\section{Norepinephrine depletion: effects on sleep and} EEG parameters

As in previous studies (Cirelli et al., 1996; Cirelli and Tononi, 2000, 2004), we found that sleep amount and distribution were unchanged 2-4 weeks after a depletion of cortical NA verified using HPLC analysis. Other laboratories have studied the effects of DSP-4 on sleep and observed either no effects or small changes, which, however, were not consistent across studies. Five days after DSP-4 treatment, Monti et al. (1988) observed a small increase in REM sleep duration during the light period. Gonzalez et al. (1998) found no changes in REM sleep duration $5 \mathrm{~d}$ after DSP-4 but a small decrease ( $\sim 20 \%)$, limited to the light phase, 15-30 d after DSP-4. Gonzalez et al. (1996, 1998) also found no 


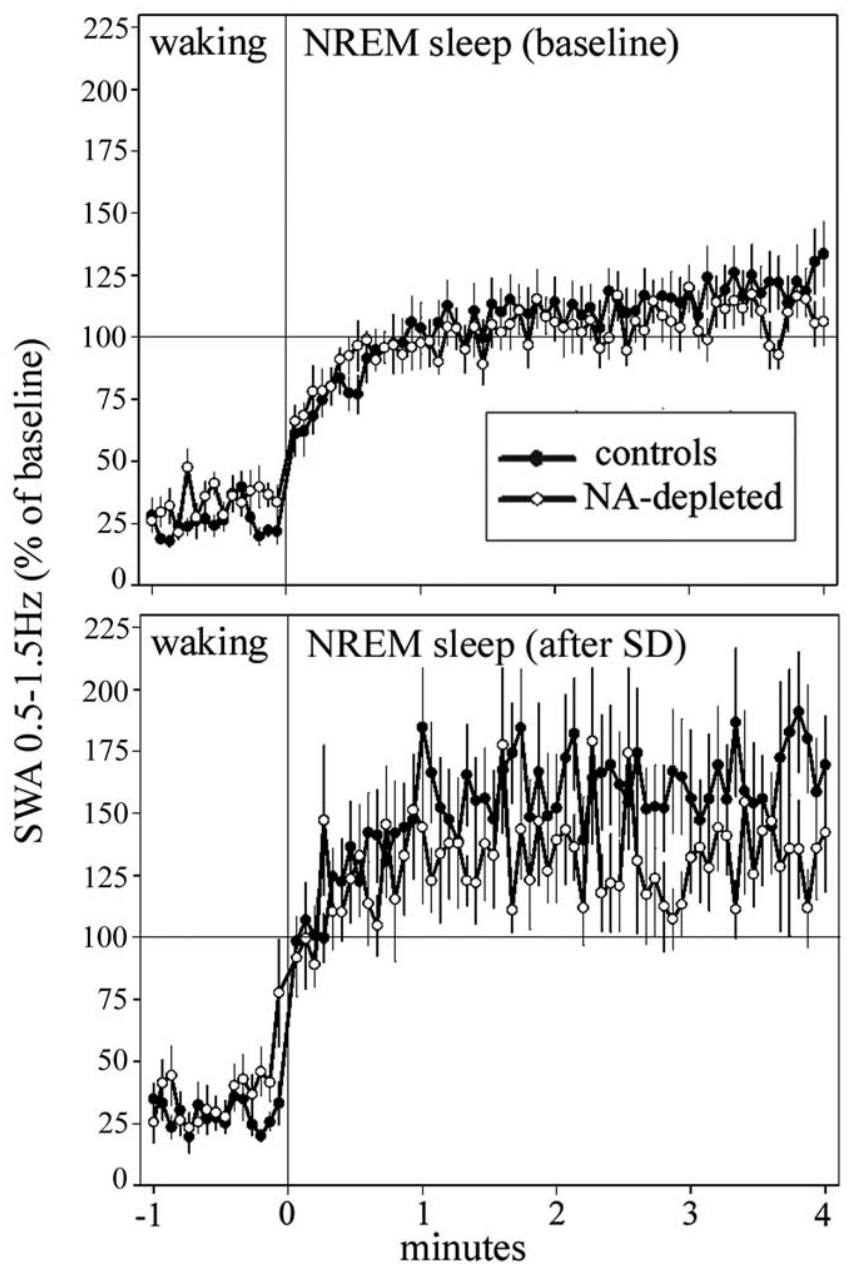

Figure 6. Time course of lower-range SWA $(0.5-1.5 \mathrm{~Hz})$ at the transition from wakefulness to NREM sleep for control $(n=13)$ and NA-depleted $(n=12)$ rats during baseline sleep (top) and during recovery sleep after sleep deprivation (SD; bottom). The curves connect mean \pm SEM $4 \mathrm{~s}$ bins for $1 \mathrm{~min}$ before and $4 \mathrm{~min}$ after the transition. The curves are expressed as a percentage of the baseline $24 \mathrm{~h}$ value of the power in NREM sleep for each animal. Mean \pm SEM number of transitions per animal: controls, baseline sleep, $21.4( \pm 1.7)$, recovery sleep, 17.1 ( \pm 1.2 ); NA-depleted rats, baseline sleep, 24.9 ( \pm 4.0$)$, recovery sleep, 15.4 ( \pm 2.7 ). As a result of the presence of artifacts in some EEG recordings, not all the animals used for Figure 5 could be used for this analysis.

change in NREM sleep duration 2 weeks after DSP-4 but a small increase $(14-23 \%)$, limited to the dark phase, 4 weeks after DSP-4. Neither Monti et al. (1988) nor Gonzalez et al. (1996, 1998) assessed the extent of the NA depletion using quantitative methods. It is likely, therefore, that some of the discrepancies are caused by different degrees of efficacy of the DSP-4 lesion. In any case, all studies agree that DSP-4 has, at most, very subtle effects on sleep duration. Moreover, our current study also confirms the findings by Gonzalez et al. $(1995,1996)$ that DSP-4 treatment has no effect on the increase in sleep duration normally observed after sleep deprivation.

We also confirm here that cortical NA depletion does not affect the overall EEG power spectrum (Cirelli et al., 1996; Cirelli and Tononi, 2000). Two other reports found no effect of DSP-4 on EEG activity (Riekkinen et al., 1990; Chang et al., 1995). Culic et al. (1995) found that the EEG power spectra in the lowerfrequency bands showed a trend $(p>0.05)$ to increase after DSP-4 treatment, but the analysis was restricted to a few $10 \mathrm{~s}$ epochs before penicillin administration in anesthetized rats.

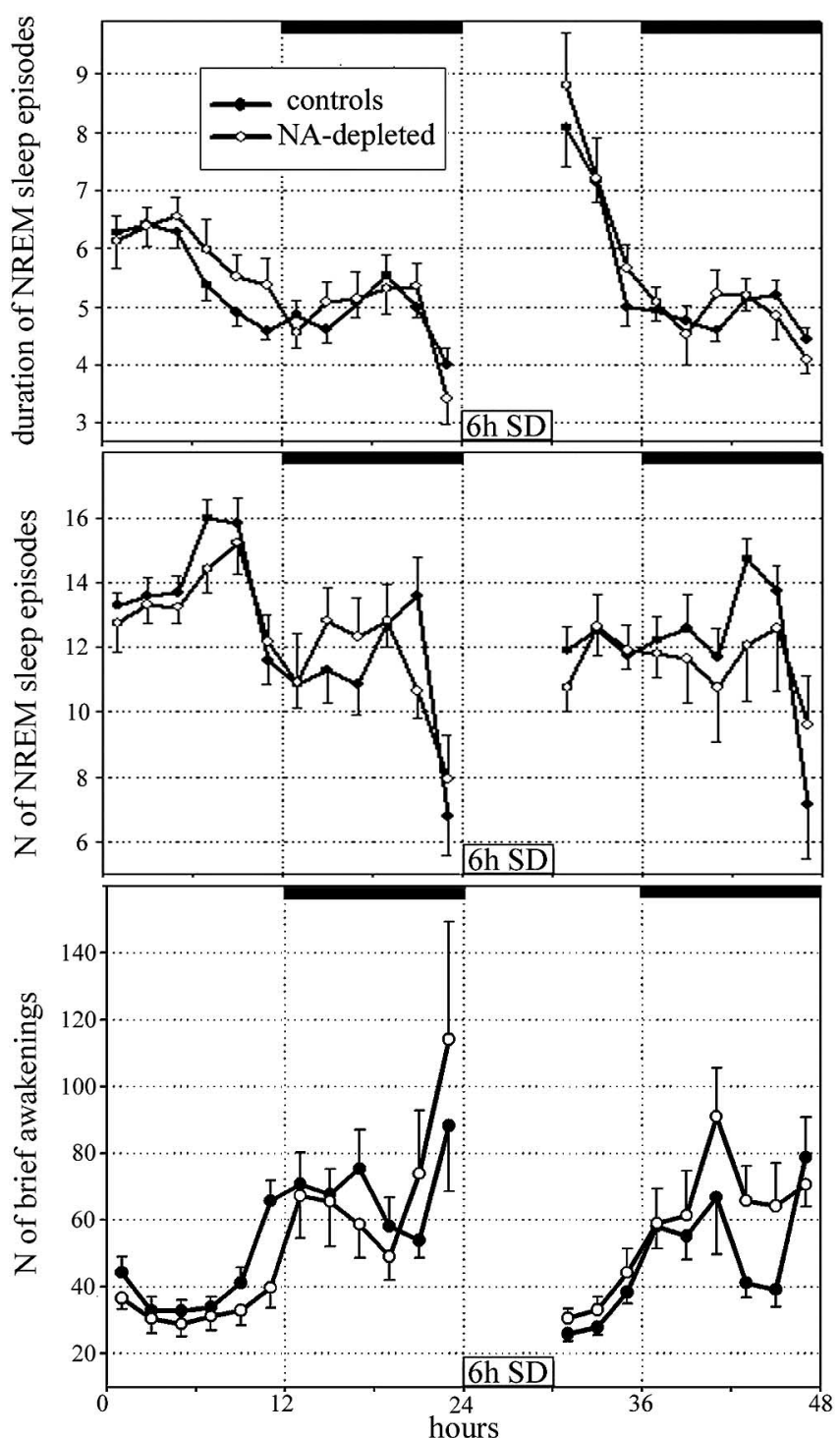

Figure 7. Top and middle, Time course of the duration and number of NREM sleep episodes during baseline and after $6 \mathrm{~h}$ of sleep deprivation (SD; controls, $n=13$; NA depleted, $n=12$ ). Curves connect $2 \mathrm{~h}$ mean values ( \pm SEM). Bottom, Time course of the number of brief awakenings during baseline and after $6 \mathrm{~h}$ of sleep deprivation (controls, $n=13$; NA depleted, $n=12$ ). The number of brief awakenings is expressed per hour of total sleep. Two-way ANOVAs showed significance for the time interval factor in all three cases (duration and number of NREM sleep episodes, number of brief awakenings), whereas the treatment factor and the treatment by time interval interaction were not significant (see Materials and Methods for details). The number of brief awakenings was still not statistically different between NA-depleted and control rats when computed for the 6 and $12 \mathrm{~h}$ periods.

Two recent studies (Hunsley and Palmiter, 2003; Ouyang et al., 2004) analyzed sleep in mice lacking the ability to make NA as a result of a targeted disruption of the gene for dopamine $\beta$-hydroxylase, which converts dopamine to NA. Daily amount of sleep was not changed in one study but increased in another, probably because of differences in genetic background (Ouyang et al., 2004). Consistent with our results, Ouyang et al. (2004) found that the increase in SWA normally observed at the transition from waking to NREM sleep was reduced in mutant mice. Moreover, as expected, in control animals, SWA was highest at the beginning of the light period and declined thereafter, whereas this did not occur in mutant mice, again in agreement with our data. Finally, after 6 h of sleep deprivation, SWA during recovery 
sleep showed a similar increase in both groups, but mutant mice had more baseline NREM sleep, and thus, most likely, they experienced a bigger sleep loss during sleep deprivation.

\section{Norepinephrine, SWA, and locomotor activity}

Two lines of evidence suggest that the blunted lower-range SWA response in DSP-4-treated rats cannot be explained by changes in locomotor activity. Although locomotor activity was not quantified in this study, it is known that DSP-4-treated animals and controls with access to running wheels exhibit similar levels of voluntary activity (Garcia et al., 2003). Most importantly, whether or not DSP-4 has locomotor effects, locomotor activity has virtually no effect on SWA (Youngstedt et al., 1997; Tobler, 2000). In rats, two studies that used forced locomotion to enforce wakefulness found that the sleep rebound was similar at different cylinder rotation rates (Borbély and Neuhaus, 1979; Friedman et al., 1979). Similarly, the amount of total sleep (Webb and Friedmann, 1969) or NREM sleep (Hanagasioglu and Borbély, 1982) was not affected by access to running wheels. In another study, there was a slightly larger SWA increase in rats sleep deprived by forced walking compared with exposure to novel objects, but the effect was minimal (170 vs $160 \%$ of baseline value) (Franken et al., 1991).

Exposure to novel objects triggered an immediate exploratory behavior in all animals, but DSP-4 treated rats lost interest in the new objects earlier than controls, in agreement with previous studies (Berridge and Dunn, 1990; Harro et al., 1995). Thus, the bilateral depletion of cortical NA by DSP-4 has consequences both at the behavioral level (reduced exploratory behavior) and at the molecular level (reduced induction of plasticity-related genes). Although it is possible that part of the observed molecular changes result indirectly from behavioral changes, the effects of NA depletion on the expression of LTP-related genes is most likely direct. This is because rats injected with the NA neurotoxin 6-OHDA in the LC of one side showed no appreciable change in exploratory behavior but a markedly reduced expression of LTPrelated genes in the ipsilateral cortex (Cirelli et al., 1996).

\section{Norepinephrine, SWA, and the "stress" response}

It has been suggested (Gonzalez et al., 1995, 1996; Charifi et al., 2000) that LC plays a role in the increase in REM sleep duration after certain acute stress manipulations. Unfortunately, SWA was not analyzed in those studies. SWA was measured, however, in another series of experiments in which rats were kept awake using manipulations involving different levels of stress (Meerlo et al., 1997, 2001). It was found that both sleep deprivation by gentle handling and by social-defeat stress increased SWA, but the latter produced a larger and/or longer-lasting increase. The more powerful effects of social conflict could not be explained by a stronger hypothalamic-pituitary-adrenocortical (HPA) response (Meerlo and Turek, 2001; Vaanholt et al., 2003) and were more likely caused by “increased cerebral activity" (Meerlo et al., 1997). This interpretation is consistent with the possibility that social conflict induces more plastic changes than gentle handling. It is worth mentioning that the HPA response in DSP-4-treated animals is indistinguishable from that in controls (Dooley et al., 1984; Bugajski et al., 1995).

\section{Norepinephrine, synaptic plasticity, and the regulation of sleep need}

What is the mechanism by which NA depletion affects the lowerrange SWA? Only a few factors are known to specifically affect SWA homeostasis, most notably growth hormone-releasing hor- mone (GHRH), interleukin-1 $\beta$ (IL-1 $\beta$ ), and adenosine. Interference with the GHRH system or with IL- $1 \beta$ expression reduces the SWA response (Obal et al., 1992; Zhang et al., 1999; Yasuda et al., 2005). However, NA depletion is unlikely to act through the GHRH system, because DSP-4 lesions spare the hypothalamic regions where GHRH-synthesizing neurons are located. Little is known about the relationship between NA and IL- $1 \beta$, but DSP-4 treatment may increase, rather than decrease, IL- $1 \beta$ expression and the inflammatory response in the cerebral cortex (Heneka et al., 2002). Finally, $A_{1}$ adenosine receptor agonists increase SWA in NREM sleep, and adenosine antagonists such as caffeine reduce the SWA response after sleep deprivation (Schwierin et al., 1996; Landolt et al., 2004) (but see Van Dongen et al., 2001). However, the mechanism by which adenosine promotes sleep is thought to involve the inhibition of the waking-promoting neurons of the basal forebrain (for review, see Basheer et al., 2004), the NA innervation of which is almost completely spared by DSP-4 lesions (Fritschy and Grzanna, 1989). Adenosine may also act at the cortical level, where it accumulates during the first $5 \mathrm{~h}$ of sleep deprivation (Porkka-Heiskanen et al., 2000). However, adenosine concentration declines during the sixth hour of sleep deprivation in the cat (Porkka-Heiskanen et al., 1997), whereas in the rat, adenosine $A_{1}$ receptor-dependent G-protein activity declines already after $3 \mathrm{~h}$ of sleep deprivation (Alanko et al., 2004). Finally, adenosine is thought to increase during waking as a byproduct of cellular energy metabolism, which is higher during waking than during sleep, but LC lesions have little or no effect on baseline brain metabolism (Savaki et al., 1984; Justice et al., 1989), do not affect brain temperature (Gonzalez et al., 1998), and do not change neocortical and hippocampal levels of cAMP, glycogen, or free fatty acids (Blomqvist et al., 1985; Busto et al., 1985).

This leaves the mechanism postulated in the Introduction, namely that NA depletion may dampen the SWA response because it reduces LTP-related changes in cortical circuits during wakefulness. NA enhances the magnitude, duration, and probability of induction of LTP in cortical and hippocampal slices, an action mediated primarily via $\beta$ adrenoceptors (Hopkins and Johnston, 1984; Stanton and Sarvey, 1985; Huang and Kandel, 1996; Thomas et al., 1996; Katsuki et al., 1997). Studies in vivo have shown that several forms of cortical plasticity require an intact NA system (for review, see Levin et al., 1988; Gu, 2002). These effects of NA on plasticity in vivo are also mediated by $\beta 1$-adrenoceptors and are probably related to the induction of LTP. Indeed, a recent study in awake rats found that LC stimulation was followed, $24 \mathrm{~h}$ later, by protein synthesis-dependent synaptic potentiation in the dentate gyrus (Walling and Harley, 2004). Finally, NA depletion prevents the expression during wakefulness of genes linked to the induction/maintenance of LTP [references in Cirelli and Tononi (2004)].

Together, the present results suggest that plastic changes that occur in the cerebral cortex during wakefulness in the presence of NA release modulate SWA homeostasis. These findings are in line with the recent demonstration that learning tasks involving a circumscribed cortical area produce a local increase in SWA (Huber et al., 2004). Thus, sleep intensity and sleep need are regulated not only by sleep centers in the hypothalamus and basal forebrain, but also by NA-gated plastic changes occurring in the very cortical circuits that generate sleep slow oscillations (Tononi and Cirelli, 2003). Consistent with this hypothesis, Hairston et al. (2004) found that in rats the period between postnatal day 15 (P15) and P20, when NA innervation of the cerebral cortex increases rapidly, coincides with the onset of waking-induced in- 
crease of cortical BDNF expression and of waking-induced SWA homeostasis. Additional tests of the hypothesis could be obtained by experimental manipulations producing an increase in the expression of LTP-related genes. Exposure to an enriched environment increases NA cortical levels (Naka et al., 2002) and induces BDNF expression (Falkenberg et al., 1992; Ickes et al., 2000). Similarly, conditional transgenic disinhibition of LC produces unilateral overexpression of plasticity-related genes (Salbaum et al., 2004). In these and similar instances, one would predict an increase in sleep SWA above and beyond what would be expected based on the duration of previous wakefulness.

\section{References}

Alanko LO, Laitinen JT, Stenberg D, Porkka-Heiskanen T (2004) Adenosine A1 receptor-dependent G-protein activity in the rat brain during prolonged wakefulness. NeuroReport 15:2133-2137.

al-Zahrani SS, al-Ruwaitea AS, Ho MY, Bradshaw CM, Szabadi E (1997) Destruction of central noradrenergic neurones with DSP4 impairs the acquisition of temporal discrimination but does not affect memory for duration in a delayed conditional discrimination task. Psychopharmacology 130:166-173.

Archer T, Mohammed AK, Ross SB, Soderberg U (1983) T-maze learning, spontaneous activity and food intake recovery following systemic administration of the noradrenaline neurotoxin, DSP4. Pharmacol Biochem Behav 19:121-130.

Aston-Jones G, Bloom FE (1981a) Activity of norepinephrine-containing locus coeruleus neurons in behaving rats anticipates fluctuations in the sleep-waking cycle. J Neurosci 1:876-886.

Aston-Jones G, Bloom FE (1981b) Norepinephrine-containing locus coeruleus neurons in behaving rats exhibit pronounced responses to nonnoxious environmental stimuli. J Neurosci 1:887-900.

Basheer R, Strecker RE, Thakkar MM, McCarley RW (2004) Adenosine and sleep-wake regulation. Prog Neurobiol 73:379-396.

Berridge CW, Dunn AJ (1990) DSP-4-induced depletion of brain norepinephrine produces opposite effects on exploratory behavior 3 and 14 days after treatment. Psychopharmacology 100:504-508.

Blomqvist P, Lindvall O, Stenevi U, Wieloch T (1985) Cyclic AMP concentrations in rat neocortex and hippocampus during and following incomplete ischemia: effects of central noradrenergic neurons, prostaglandins, and adenosine. J Neurochem 44:1345-1353.

Borbély AA, Achermann P (2000) Sleep homeostasis and models of sleep regulation. In: Principles and practice of sleep medicine (Kryger $\mathrm{MH}$, Roth T, Dement WC, eds), pp 377-390. Philadelphia: Saunders.

Borbély AA, Neuhaus HU (1979) Sleep deprivation: effects on sleep and EEG in the rat. J Comp Physiol 133:71-87.

Bugajski J, Gadek-Michalska A, Olowska A, Borycz J, Glod R, Bugajski AJ (1995) Adrenergic regulation of the hypothalamic-pituitary-adrenal axis under basal and social stress conditions. J Physiol Pharmacol 46:297-312.

Busto R, Harik SI, Yoshida S, Scheinberg P, Ginsberg MD (1985) Cerebral norepinephrine depletion enhances recovery after brain ischemia. Ann Neurol 18:329-336.

Chang AY, Kuo TB, Tsai TH, Chen CF, Chan SH (1995) Power spectral analysis of electroencephalographic desynchronization induced by cocaine in rats: correlation with evaluation of noradrenergic neurotransmission at the medial prefrontal cortex. Synapse 21:149-157.

Charifi C, Paut-Pagano L, Debilly G, Cespuglio R, Jouvet M, Valatx JL (2000) Effect of noradrenergic denervation of the amygdala upon recovery after sleep deprivation in the rat. Neurosci Lett 287:41-44.

Cirelli C, Tononi G (2000) Differential expression of plasticity-related genes in waking and sleep and their regulation by the noradrenergic system. J Neurosci 20:9187-9194.

Cirelli C, Tononi G (2004) Locus ceruleus control of state-dependent gene expression. J Neurosci 24:5410-5419.

Cirelli C, Pompeiano M, Tononi G (1996) Neuronal gene expression in the waking state: a role for the locus coeruleus. Science 274:1211-1215.

Cirelli C, Gutierrez CM, Tononi G (2004) Extensive and divergent effects of sleep and wakefulness on brain gene expression. Neuron 41:35-43.

Clayton EC, Rajkowski J, Cohen JD, Aston-Jones G (2004) Phasic activation of monkey locus ceruleus neurons by simple decisions in a forced-choice task. J Neurosci 24:9914-9920.

Culic M, Saponjic J, Jankovic B, Udovic S, Popovic S, Rakic L (1995) Effect of neurotoxin DSP4 on EEG power spectra in the rat acute model of epilepsy. Neurosci Lett 196:49-52.

Daan S, Beersma DG, Borbély AA (1984) Timing of human sleep: recovery process gated by a circadian pacemaker. Am J Physiol 246:R161-R183.

Dooley DJ, Hunziker G, Hausler A (1984) Corticosterone secretion in the rat after DSP-4 treatment. Neurosci Lett 46:271-274.

Dudley MW, Howard BD, Cho AK (1990) The interaction of the betahaloethyl benzylamines, xylamine, and DSP-4 with catecholaminergic neurons. Annu Rev Pharmacol Toxicol 30:387-403.

Falkenberg T, Mohammed AK, Henriksson B, Persson H, Winblad B, Lindefors N (1992) Increased expression of brain-derived neurotrophic factor mRNA in rat hippocampus is associated with improved spatial memory and enriched environment. Neurosci Lett 138:153-156.

Feinberg I, Thode Jr HC, Chugani HT, March JD (1990) Gamma distribution model describes maturational curves for delta wave amplitude, cortical metabolic rate and synaptic density. J Theor Biol 142:149-161.

Franken P, Dijk DJ, Tobler I, Borbély AA (1991) Sleep deprivation in rats: effects on EEG power spectra, vigilance states, and cortical temperature. Am J Physiol 261:R198-R208.

Friedman L, Bergmann BM, Rechtschaffen A (1979) Effects of sleep deprivation on sleepiness, sleep intensity, and subsequent sleep in the rat. Sleep 1:369-391.

Fritschy JM, Grzanna R (1989) Immunohistochemical analysis of the neurotoxic effects of DSP-4 identifies two populations of noradrenergic axon terminals. Neuroscience 30:181-197.

Fritschy JM, Grzanna R (1992) Restoration of ascending noradrenergic projections by residual locus coeruleus neurons: compensatory response to neurotoxin-induced cell death in the adult rat brain. J Comp Neurol 321:421-441.

Fuertes G, Laorden ML, Milanes MV (2000) Noradrenergic and dopaminergic activity in the hypothalamic paraventricular nucleus after naloxone-induced morphine withdrawal. Neuroendocrinology 71:60-67.

Garcia C, Chen MJ, Garza AA, Cotman CW, Russo-Neustadt A (2003) The influence of specific noradrenergic and serotonergic lesions on the expression of hippocampal brain-derived neurotrophic factor transcripts following voluntary physical activity. Neuroscience 119:721-732.

Gonzalez MM, Debilly G, Valatx JL, Jouvet M (1995) Sleep increase after immobilization stress: role of the noradrenergic locus coeruleus system in the rat. Neurosci Lett 202:5-8.

Gonzalez MM, Valatx JL, Debilly G (1996) Role of the locus coeruleus in the sleep rebound following two different sleep deprivation methods in the rat. Brain Res 740:215-226.

Gonzalez MM, Debilly G, Valatx JL (1998) Noradrenaline neurotoxin DSP-4 effects on sleep and brain temperature in the rat. Neurosci Lett 248:93-96.

Gu Q (2002) Neuromodulatory transmitter systems in the cortex and their role in cortical plasticity. Neuroscience 111:815-835.

Hairston IS, Peyron C, Denning DP, Ruby NF, Flores J, Sapolsky RM, Heller HC, O'Hara BF (2004) Sleep deprivation effects on growth factor expression in neonatal rats: a potential role for BDNF in the mediation of delta power. J Neurophysiol 91:1586-1595.

Hanagasioglu M, Borbély AA (1982) Effect of voluntary locomotor activity on sleep in the rat. Behav Brain Res 4:359-368.

Harro J, Oreland L, Vasar E, Bradwejn J (1995) Impaired exploratory behaviour after DSP-4 treatment in rats: implications for the increased anxiety after noradrenergic denervation. Eur Neuropsychopharmacol 5:447-455.

Heneka MT, Galea E, Gavriluyk V, Dumitrescu-Ozimek L, Daeschner J, O’Banion MK, Weinberg G, Klockgether T, Feinstein DL (2002) Noradrenergic depletion potentiates $\beta$-amyloid-induced cortical inflammation: implications for Alzheimer's disease. J Neurosci 22:2434-2442.

Hill SL, Tononi G (2005) Modeling sleep and wakefulness in the thalamocortical system. J Neurophysiol 93:1671-1698.

Ho MY, Velazquez Martinez DN, Lopez Cabrera M, al-Zahrani SS, Bradshaw CM, Szabadi E (1995) Retarded acquisition of a temporal discrimination following destruction of noradrenergic neurones by systemic treatment with DSP4. Psychopharmacology 118:332-337.

Hobson JA, McCarley RW, Wyzinski PW (1975) Sleep cycle oscillation: reciprocal discharge by two brainstem neuronal groups. Science 189:55-58. Hopkins WF, Johnston D (1984) Frequency-dependent noradrenergic modulation of long-term potentiation in the hippocampus. Science 226:350-352.

Huang Y-Y, Kandel ER (1996) Modulation of both the early and the late 
phase of mossy fiber LTP by the activation of $\beta$-adrenergic receptors. Neuron 16:611-617.

Huber R, Deboer T, Tobler I (2000) Topography of EEG dynamics after sleep deprivation in mice. J Neurophysiol 84:1888-1893.

Huber R, Ghilardi MF, Massimini M, Tononi G (2004) Local sleep and learning. Nature 430:78-81.

Hunsley MS, Palmiter RD (2003) Norepinephrine-deficient mice exhibit normal sleep-wake states but have shorter sleep latency after mild stress and low doses of amphetamine. Sleep 26:521-526.

Ickes BR, Pham TM, Sanders LA, Albeck DS, Mohammed AH, Granholm AC (2000) Long-term environmental enrichment leads to regional increases in neurotrophin levels in rat brain. Exp Neurol 164:45-52.

Justice A, Feldman SM, Brown LL (1989) The nucleus locus coeruleus modulates local cerebral glucose utilization during noise stress in rats. Brain Res 490:73-84.

Katsuki H, Izumi Y, Zorumski CF (1997) Noradrenergic regulation of synaptic plasticity in the hippocampal CA1 region. J Neurophysiol 77:3013-3020.

Landolt HP, Retey JV, Tonz K, Gottselig JM, Khatami R, Buckelmuller I, Achermann P (2004) Caffeine attenuates waking and sleep electroencephalographic markers of sleep homeostasis in humans. Neuropsychopharmacology 29:1933-1939.

Levin BE, Craik RL, Hand PJ (1988) The role of norepinephrine in adult rat somatosensory $(\mathrm{SmI})$ cortical metabolism and plasticity. Brain Res 443:261-271.

Matsukawa M, Nakadate K, Ishihara I, Okado N (2003) Synaptic loss following depletion of noradrenaline and/or serotonin in the rat visual cortex: a quantitative electron microscopic study. Neuroscience 122:627-635.

Meerlo P, Turek FW (2001) Effects of social stimuli on sleep in mice: nonrapid-eye-movement (NREM) sleep is promoted by aggressive interaction but not by sexual interaction. Brain Res 907:84-92.

Meerlo P, Pragt BJ, Daan S (1997) Social stress induces high intensity sleep in rats. Neurosci Lett 225:41-44.

Meerlo P, de Bruin EA, Striikstra AM, Daan S (2001) A social conflict increases EEG slow-wave activity during subsequent sleep. Physiol Behav 73:331-335.

Monti JM, D’Angelo L, Jantos H, Barbeito L, Abo V (1988) Effect of DSP-4, a noradrenergic neurotoxin, on sleep and wakefulness and sensitivity to drugs acting on adrenergic receptors in the rat. Sleep 11:370-377.

Naka F, Shiga T, Yaguchi M, Okado N (2002) An enriched environment increases noradrenaline concentration in the mouse brain. Brain Res 924:124-126.

Obal Jr F, Payne L, Opp M, Alfoldi P, Kapas L, Krueger JM (1992) Growth hormone-releasing hormone antibodies suppress sleep and prevent enhancement of sleep after sleep deprivation. Am J Physiol 263:R1078-R1085.

Ogren SO, Archer T, Ross SB (1980) Evidence for a role of the locus coeruleus noradrenaline system in learning. Neurosci Lett 20:351-356.

Ouyang M, Hellman K, Abel T, Thomas SA (2004) Adrenergic signaling plays a critical role in the maintenance of waking and in the regulation of REM sleep. J Neurophysiol 92:2071-2082.

Porkka-Heiskanen T, Strecker RE, Thakkar M, Bjorkum AA, Greene RW, McCarley RW (1997) Adenosine: a mediator of the sleep-inducing effects of prolonged wakefulness. Science 276:1265-1268.

Porkka-Heiskanen T, Strecker RE, McCarley RW (2000) Brain sitespecificity of extracellular adenosine concentration changes during sleep deprivation and spontaneous sleep: an in vivo microdialysis study. Neuroscience 99:507-517.

Rajkowski J, Majczynski H, Clayton E, Aston-Jones G (2004) Activation of monkey locus coeruleus neurons varies with difficulty and performance in a target detection task. J Neurophysiol 92:361-371.

Riekkinen Jr P, Sirvio J, Valjakka A, Pitkanen A, Partanen J, Riekkinen P (1990) The effects of concurrent manipulations of cholinergic and nor- adrenergic systems on neocortical EEG and spatial learning. Behav Neural Biol 54:204-210.

Riekkinen Jr P, Riekkinen M, Valjakka A, Riekkinen P, Sirvio J (1992) DSP-4, a noradrenergic neurotoxin, produces more severe biochemical and functional deficits in aged than young rats. Brain Res 570:293-299.

Robbins TW, Everitt BJ (1995) Central noradrenaline neurons and behavior. In: Psychopharmacology: the fourth generation of progress (Bloom FE, Kupfer DJ, eds), pp 363-372. New York: Raven.

Salbaum JM, Cirelli C, Walcott E, Krushel LA, Edelman GM, Tononi G (2004) Chlorotoxin-mediated disinhibition of noradrenergic locus coeruleus neurons using a conditional transgenic approach. Brain Res 1016:20-32.

Savaki HE, Graham DI, Grome JJ, McCulloch J (1984) Functional consequences of unilateral lesion of the locus coeruleus: a quantitative [14C]2deoxyglucose investigation. Brain Res 292:239-249.

Schwierin B, Borbély AA, Tobler I (1996) Effects of N6-cyclopentyladenosine and caffeine on sleep regulation in the rat. Eur J Pharmacol 300:163-171.

Stanton PK, Sarvey JM (1985) Depletion of norepinephrine, but not serotonin, reduces long-term potentiation in the dentate gyrus of rat hippocampal slices. J Neurosci 5:2169-2176.

Steriade M, Timofeev I, Grenier F (2001) Natural waking and sleep states: a view from inside neocortical neurons. J Neurophysiol 85:1969-1985.

Thomas MJ, Moody TD, Makhinson M, O’Dell TJ (1996) Activitydependent beta-adrenergic modulation of low frequency stimulation induced LTP in the hippocampal CA1 region. Neuron 17:475-482.

Tobler I (2000) Phylogeny of sleep regulation. In: Principles and practice of sleep medicine (Kryger MH, Roth T, Dement WC, eds), pp 72-81. Philadelphia: Saunders.

Tobler I, Borbély AA (1990) The effect of 3-h and 6-h sleep deprivation on sleep and EEG spectra of the rat. Behav Brain Res 36:73-78.

Tobler I, Franken P, Alfoldi P, Borbély AA (1994) Room light impairs sleep in the albino rat. Behav Brain Res 63:205-211.

Tobler I, Deboer T, Fischer M (1997) Sleep and sleep regulation in normal and prion protein-deficient mice. J Neurosci 17:1869-1879.

Tononi G, Cirelli C (2003) Sleep and synaptic homeostasis: a hypothesis. Brain Res Bull 62:143-150.

Turrigiano GG (1999) Homeostatic plasticity in neuronal networks: the more things change, the more they stay the same. Trends Neurosci 22:221-227.

Vaanholt LM, Turek FW, Meerlo P (2003) Beta-endorphin modulates the acute response to a social conflict in male mice but does not play a role in stress-induced changes in sleep. Brain Res 978:169-176.

Van Dongen HP, Price NJ, Mullington JM, Szuba MP, Kapoor SC, Dinges DF (2001) Caffeine eliminates psychomotor vigilance deficits from sleep inertia. Sleep 24:813-819.

Yamamoto M, Imamura K, Kobayashi M, Nakadate K, Yokoyama C, Watanabe Y, Yamamoto M, Negi A (2001) N-(2-Chloroethyl)- $N$-ethyl-2bromobenzylamine reduces intracellular calcium response to noradrenaline in rat visual cortex. Neuroscience 107:209-218.

Yasuda T, Yoshida H, Garcia-Garcia F, Kay D, Krueger JM (2005) Interleukin- $1 \mathrm{~b}$ has a role in cerebral cortical state-dependent electroencephalographic slow-wave activity. Sleep 28:177-184.

Youngstedt SD, O'Connor PJ, Dishman RK (1997) The effects of acute exercise on sleep: a quantitative synthesis. Sleep 20:203-214.

Walling SG, Harley CW (2004) Locus ceruleus activation initiates delayed synaptic potentiation of perforant path input to the dentate gyrus in awake rats: a novel $\beta$-adrenergic- and protein synthesis-dependent mammalian plasticity mechanism. J Neurosci 24:598-604.

Webb WB, Friedmann J (1969) Activity as a determinant of sleep in rats. Psychophysiology 6:272.

Zhang J, Obal Jr F, Zheng T, Fang J, Taishi P, Krueger JM (1999) Intrapreoptic microinjection of GHRH or its antagonist alters sleep in rats. J Neurosci 19:2187-2194. 